\title{
Research on women in science and higher education: a bibliometric analysis
}

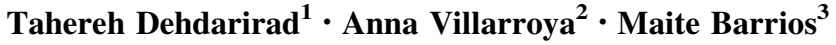

Received: 12 May 2014

(C) Akadémiai Kiadó, Budapest, Hungary 2015

\begin{abstract}
The main objective of this paper is to study the development and growth of scientific literature on women in science and higher education. A total of 1415 articles and reviews published between 1991 and 2012 were extracted from the Thomson Reuters Web of Science database. Standard bibliometric indicators and laws (e.g. Price's, Lotka's, and Bradford's laws) were applied to these data. In addition, the Gender Inequality Index (GII) was obtained for each country in order to rank them. The results suggest an upward trend not only in the number of papers but also in the number of authors per paper. However, this increase in the number of authors was not accompanied by greater international collaboration. The interest in gender differences in science extends too many authors $(n=3064)$, countries $(n=67)$, and research areas $(n=86)$. Data showed a high dispersion of the literature and a small set of core journals focused on the topic. Regarding the research areas, the area with the highest frequency of papers was Education and Educational Research. Finally, our results showed that countries with higher levels of inequality (higher GII values) tend to present higher relative values of scientific productivity in the field.
\end{abstract}

Keywords Gender differences · Higher education - Science · Bibliometrics

Mathematics Subject Classification $\quad 01-00 \cdot 62-07$

JEL Classification $\mathrm{C} 10 \cdot \mathrm{O} 30$

Maite Barrios

mbarrios@ub.edu

1 Department of Library and Information Science, University of Barcelona, Barcelona, Spain

2 Department of Public Economy, Political Economy and Spanish Economy, University of Barcelona, Barcelona, Spain

3 Department of Methodology of the Behavioural Sciences, University of Barcelona, Passeig de la Vall d'Hebron 171, 08035 Barcelona, Spain 


\section{Introduction}

According to the latest indicators referred to the European Union, although women's entry into and progression within science is progressing towards a more equal representation, they are still under-represented in leading positions (European Commission 2013). As a consequence, numerous reports and initiatives have emerged in Europe but also in different parts of the world with the aim of analyzing the presence of women in science and higher education (WSHE), and to advocate for a more gender-balanced structure of science (LERU 2012; Deloitte Consulting 2013; European Commission 2013; the Organization for Economic Co-operation and Development [OECD] 2013).

The scientific literature contains ample evidence regarding different aspects of women's participation and performance in science and higher education. A significant body of studies has examined gender disparities in publication productivity, addressing issues such as the number of publications, citations, impact of researchers' output, and patterns of collaboration. In terms of the number of publications many studies have demonstrated that female academics publish less, on average, than do their male colleagues (Braisher et al. 2005; Kelly and Jennions 2006; Symonds et al. 2006; Sidhu et al. 2009; Jagsi et al. 2011; Schrager et al. 2011). However, there is also research reporting no significant differences in productivity between the two sexes (Xie and Shauman 1998; Lewison 2001; Bordons et al. 2003; Tower et al. 2007; Mauleón et al. 2008), especially when it comes to younger generations of researchers (Arensbergen et al. 2012). Some of these studies have also evaluated the impact of publications, through the number of citations or the journal impact factor. The literature in this area has shown mixed results, including no differences in the citation patterns of male and female academics (Cole and Zuckerman 1984; Lewison 2001; Ledin et al. 2007; Mauleón et al. 2008; Copenheaver et al. 2010), a higher number of citations for female-authored papers (Long 1992; Symonds et al. 2006; Borrego et al. 2010), and fewer citations of papers authored by women (Hunter and Leahey 2010; Larivière et al. 2011, 2013a, b). Recently, the global, cross-disciplinary bibliometric study undertaken by Larivière et al. (2013a, b) showed that papers with female authors in key positions (sole authorship, first- and last-authorship) are cited less than those with males in key positions.

Studies on the journal impact factor have also produced mixed findings: while some of them have highlighted the similarity of the journals in which women and men publish (Lewison 2001; Bordons et al. 2003; Mauleón and Bordons 2006; Gonzalez-Brambila and Veloso 2007; Mauleón et al. 2008), others have shown that men choose to publish in journals with a higher impact factor (Hunter and Leahey 2010), or alternatively that women are the ones who tend to publish in higher impact journals (Borrego et al. 2010). Another approach to the study of scientific activity concerns the collaborative practices of researchers. Here, there is ample evidence showing that women collaborate to a lesser extent than do men with foreign authors (Lemoine 1992; Lewison 2001; Webster 2001; Larivière et al. 2011, 2013a, b). However, the results on authorship patterns have proved inconclusive: whilst some research has obtained similar rates of co-authorship among women and men (Maske et al. 2003; McDowell et al. 2006), other studies have found significantly lower rates of co-authorship for women (Boschini and Sjögren 2007; West et al. 2013; Larivière et al. 2013a, b). Another sizeable body of research on WSHE has addressed elements that have an influence on the development of a scientific career, such as grant and manuscript reviewing, access to funding and hiring and career progression. With regard to manuscript reviewing, Budden et al. (2008) reported that the acceptance rate for 
female first-authored manuscripts increased after the onset of blind review, suggesting that when reviewers were aware of the authors' sex they were less likely to accept manuscripts from women. However, further work on this issue has found no differences in the acceptance/rejection ratio for papers submitted by male and female corresponding authors (Aarssen et al. 2008; Whittaker 2008). The situation is different in relation to the participation of women in peer review processes, where many more authors have found gender differences in female recruitment as editors and reviewers (Gilbert et al. 1994; Dickersin et al. 1998; Davo et al. 2003). Concerning grant peer reviewing, one of the most frequently cited studies on gender bias, that carried out by Wennerås and Wold (1997), demonstrated that female applicants for postdoctoral fellowships at the Swedish Medical Research Council had to be 2.5 times more productive than the average male applicant in order to obtain the same peer-review rating for scientific competence. Since then, an evergrowing body of academic research has found no conclusive evidence of sex discrimination in the awarding of specific project grants (Wellcome Trust 1997; Ward and Donnelly 1998; Bornmann et al. 2007; Marsh et al. 2008). In this regard, the meta-analyses conducted by Bornmann et al. (2007) and Marsh et al. (2009), and more recently the study by Mutz et al. (2012), have all concluded that there is negligible evidence of gender bias in grant awarding programs. There is also a body of academic literature attesting to the idea that male scientists face fewer difficulties when seeking to access financial support and better facilities (Stack 2004; Larivière et al. 2011; LERU 2012), since they occupy a greater proportion of high positions from which it is possible to apply for and receive larger grants (Blake and La Valle 2000; Waisbren et al. 2008; Ranga et al. 2012). Other aspects that have been clearly highlighted in the literature are the overrepresentation of women in lower faculty ranks (D'Amico et al. 2011), due to the difficulties of progressing up the academic ladder (LERU 2012), a persistent gender pay gap (Ward 2001; Ginther 2003; Henderson et al. 2014), and gender bias in researcher recruitment (Andersen 2001), especially in certain male-dominated areas (Isaac et al. 2009). Recent research suggests that many mechanisms prevalent in recruitment and appointment practices of professors result in disadvantages for women and privileges for men (Van den Brink 2011). These mechanisms include "gate keeping", academic networks that are male-dominated and the way scientific excellence is defined (LERU 2012). Based on an empirical study of professorial appointments in the Netherlands, Van den Brink and Benschop (2012) show how gender bias is practised in the evaluation of professorial candidates, resulting in substantial inequalities in the construction of excellence.

As the above-mentioned evidence suggests, different studies have reported diverse results. Hence, many of these studies have sought to explain the systematic disparities between men and women by incorporating different factors into their analysis. Factors surrounding family formation and childrearing have been one of the major causes of female underrepresentation in academia evidenced by the literature (Sax et al. 2002; Stack 2004; Fox 2005; Ginther and Kahn 2006; Prozesky 2008; Hunter and Leahey 2010). Another large body of literature has focused on structural factors such as the greater presence of women in less research-oriented institutions (Allison and Long 1990; Xie and Shauman 1998), the higher teaching and service load among females (Taylor et al. 2006; Snell et al. 2009; DesRoches et al. 2010), their lower degree of specialization (Leahey 2006) and of academic status and rank (Leta and Lewison 2003; Tower et al. 2007; Puuska 2010; Pashkova et al. 2013), their difficulties in accessing funding (Xie and Shauman 1998), the low percentage of women on selection committees (European Commission 2009; Zinovyeva and Bagues 2011), or the academic assessment systems that have traditionally ignored factors that especially affect women (LERU 2012). From a 
psychological perspective, gender differences have been explained by women's lower levels of career orientation, ambition, and aggressiveness (Sonnert 1996). Similarly, career preferences, ability, and biological differences have been key factors proposed to explain female underrepresentation in science, technology, engineering, and mathematics (STEM) disciplines. Finally, there is also a body of academic research attesting to overt or unconscious gender bias as the main factor against retention and progression of female scientists in academia (Dewandre 2002; Moss-Racusin et al. 2012; Shen 2013).

Despite the relevance of the issue and the number of academic publications, initiatives, and reports on WSHE, no systematic analysis has yet to be carried out of the large body of research in this area. Using standard bibliometric indicators (such as the number of papers and authors, and productivity by country, among others), laws (Price's, Lotka's, and Bradford's laws) and an index for measuring gender disparity [the Gender Inequality Index (GII)], this article aims to assess the development and growth of research in this field by reviewing the related scientific literature.

\section{Methods}

\section{Data collection}

The data were extracted from the Thomson Reuters Web of Science (WOS) in February 2013, with the search in the topic field covering the period from 1991 to 2012. Several strategies were used to retrieve the related scientific literature (Fig. 1). First, three different searches were carried out, taking into account the three main topics in the field: publication

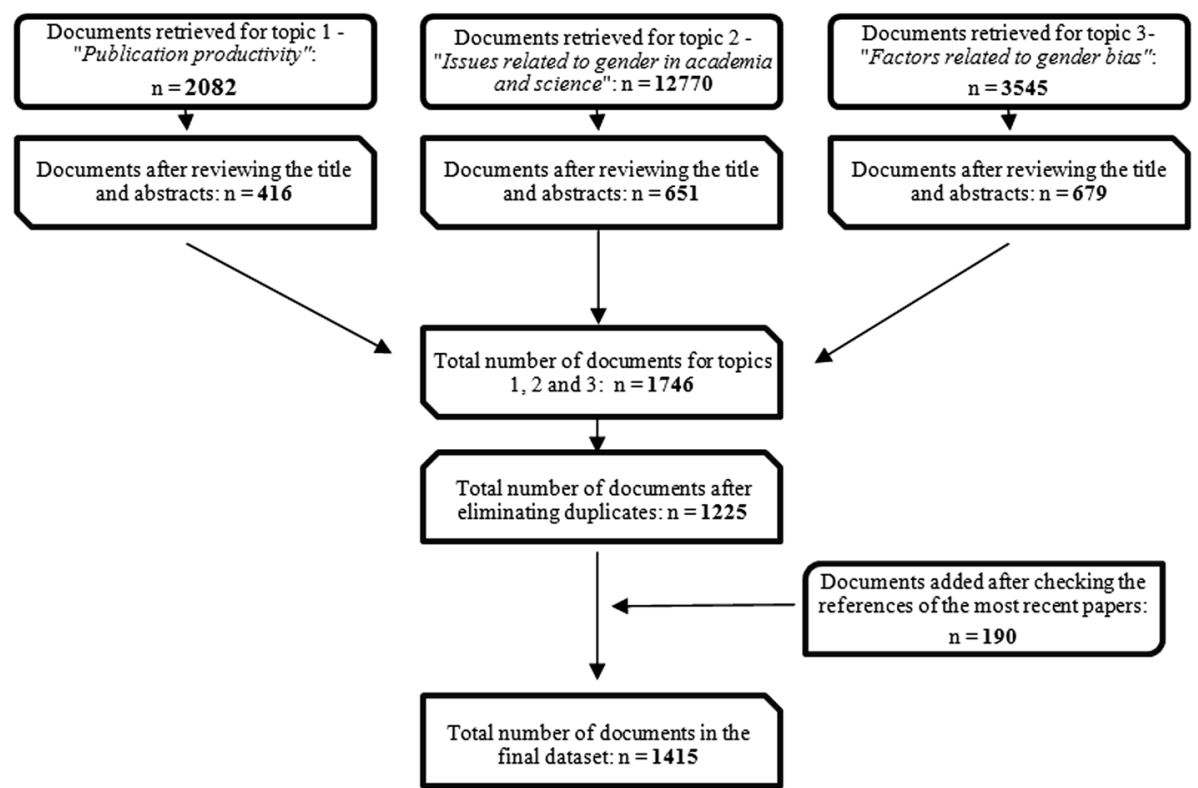

Fig. 1 Flowchart illustrating the process of data collection 
productivity, issues related to gender in academia and science, and factors related to gender bias.

To do so, for each topic we went through the related literature in order to identify the related key terms. A preliminary combination of key terms was used to extract the papers related to the subject. Next, after reviewing the keywords of these preliminary papers, we added more specific terms to the query in order to check whether these new terms increased the number of records retrieved; if they did, they were included in the query, and if not, they were eliminated.

By publication productivity we refer to those papers dealing with scientific productivity, citation, and collaboration patterns. Papers addressing elements other than publication productivity that have an influence on the development of a scientific career, such as interviewing and hiring, salaries, promotion and advancement, having access to funding, mentoring and networking, and being a member of an editorial board or a peer reviewer were categorized in the second group, labeled issues related to gender in academia and science. Finally, given that the performance of researchers in the two above-mentioned groups of scientific activities can be affected by several factors, another pool of papers were considered as a third group called factors related to gender bias. Among these factors we took into account family-related issues (e.g. marital status, childrearing activities, home stress, family formation, work-home balance, etc.), structural or institutional variables (e.g. type of institution, research support, academic system, etc.), professional issues (e.g. job stress, motivation, rank, research orientation, etc.), biological factors (e.g. age, race, etc.), psychological traits (e.g. self-esteem, ambition, aggressiveness, etc.), social and cultural factors (e.g. stereotypes, norms and values, etc.) and political variables (policies and legislation regarding WSHE).

As a result of this step, 2082 records were initially retrieved for the first topic, 12,770 for the second and 3545 for the third. In order to identify the papers related to these three main topics the titles and abstracts of each paper were checked. Papers which focused on the field of higher education and science, dealt with one or more of above three topics mentioned, and in which gender was one of the variables of interest, were included in the sample.

Finally, a total of 1746 papers were retrieved: $416(23.83 \%)$ records for the publication productivity topic, 651 (37.29\%) records for the issues related to gender in academia and science topic, and $679(38.88 \%)$ records for the factors related to gender bias topic. After elimination of duplicates a total of 1225 records were considered. Additionally, and in order to ensure that all the references dealing with the subject were included in the database, the references of the most recent papers were checked. If any new paper was found it was added to the database, and we continued doing this until no new references were identified. This process led to the inclusion of 190 new papers. As a result the final corpus comprised 1415 articles and reviews, all of which were coded according to the three headings mentioned above. It should be noted that any given paper may simultaneously address more than one issue, and it will therefore belong to more than one group.

\section{Data analysis}

The main bibliometric laws were applied to study scientific growth over time, the dispersion of scientific output across journals, and author productivity.

Scientific growth over time was assessed using Price's law (Price 1963), which proposes that the growth of scientific production follows an exponential function. In order to test whether our data followed Price's law, different regression models were fitted, including 
linear, exponential and logistic curves, the latter being applied to assess the hypothesis of literature growth saturation.

Bradford's law (Bradford 1934, 1948) was applied in order to study the dispersion of the literature. Specifically, Bradford's law describes how the articles in a specific area are scattered across journals, postulating a model of concentric productivity zones with a decreasing information density. Following the proposal of Egghe (1986, 1990), the Bradford multiplier was obtained by $k=\left(1.781 \times y_{\mathrm{m}}\right)^{1 / P}$ where $y_{\mathrm{m}}$ is the number of articles published by the most productive journal and $P$ is the number of zones including the core. The estimated $k$ value for each zone was calculated by the ratio between the number of journals in a given zone and the number of journals in any immediate zone. The number of Bradford zones was determined by the solution that minimized the difference between the Bradford multiplier $k$ and each estimated value of $k$, and between the estimated values of $k$.

In addition, the predicted frequencies were fitted according to Leimkuhler's formulation (Leimkuhler 1967), obtaining the constants as $A=y_{0} / \log _{e} k$ and $B=(k-1) / r_{0}$ where $y_{0}$ is the constant number of articles in each group $\left(y_{0=a / P}\right.$, where $a$ is the total number of articles and both $P$ and $k$ are as defined above) and $r_{0}$ is the expected number of journals in the core $\left(r_{0}=\frac{T(K-1)}{k^{p}-1}\right.$, where $T$ is the total number of journals, and $k$ and $P$ are as defined above). The estimated cumulative number of articles produced by the journals of rank $1,2, \ldots, r$ was obtained by: $R(r)=A \times \log _{e}(1+B \times r)$.

After standardization of authors' names (we began with a total of 3538 authors and after standardization we ended with a total of 3064 single authors), Lotka's law was also applied using the method proposed by Pao (1985), including both the first author and co-authors in the analysis. According to Lotka's law the number of authors $\left(y_{x}\right)$ with $x$ number of articles is inversely proportional to $x$. This relationship is expressed by the formula:

$$
x^{n} \times y_{x}=C,
$$

where $y_{x}$ is the number of authors producing $x$ number of articles in a given research field, and $\mathrm{C}$ and $n$ are constants that can be calculated from the observed data set.

In our study, we used the least-squares method in order to calculate the $n$ exponent, using the following formula:

$$
N=\frac{N \sum X Y-\sum X \sum Y}{N \sum X^{2}-\left(\sum X\right)^{2}}
$$

where $N$ is the number of pairs considered, $X$ is the logarithm of $x$ and $Y$ is the logarithm of $y_{x}$. The constant $C$ is calculated using the formula:

$$
C=\frac{1}{\sum\left(1 / x^{n}\right)}
$$

In addition, and in order to verify that the observed data fitted the estimated distribution, the non-parametric Kolmogorov-Smirnov goodness-of-fit test was applied.

In order to calculate relative measures of productivity and international collaboration productivity by country, the Relative Intensity Index (RII) (Larivière et al. 2013a, b) and the International Collaboration Relative Intensity Index (IC-RII) were calculated for each country. Both measures indicate the relative proportion of publications of a given country in a domain relative to the proportion of the world in the same domain. Thus, the RII indicates the relative proportion of publications of a given country in the WSHE area 
relative to the proportion of the world in the same domain. The RII was calculated for each country using the following formula:

$$
\mathrm{RII}=\frac{\frac{n_{\mathrm{WSHE} \text { country }}}{n_{\text {country }}}}{\frac{n_{\mathrm{WSHE} \text { world }}}{n_{\text {world }}}}
$$

where $n_{\text {WSHE country }}$ is the number of publications of a given country in the WSHE area, $n_{\text {country }}$ is the total number of publications of the country in all disciplines, $n_{\text {WSHE world }}$ is the total publications of the world dealing with WSHE, and $n_{\text {world }}$ is the total of publications in all disciplines in the world.

The IC-RII indicates the relative proportion of publications of a country in the WSHE area in international collaboration relative to the proportion of the world's publications published through international collaboration in the same area. The IC-RII is expressed by the formula:

$$
\text { IC-RII }=\frac{\frac{n_{\mathrm{IC} \_ \text {wSHE country }}}{n_{\mathrm{IC} \_ \text {country }}}}{\frac{n_{\mathrm{IC}} \text { WSHE world }}{n_{\mathrm{IC} \_ \text {world }}}}
$$

where all terms have the same meaning as above except this time publications include only those carried out through international collaboration.

In both cases a value above 1 means that an observed country publishes more in the domain than would be expected, while an index value below 1 indicates the opposite.

It is worth saying that by "World" in our study we mean just those countries which contributed to the publication productivity in WSHE, while by the number of papers we mean the number of scientific papers by authors from a given country, as indicated in the address field. To do so, we used the full counting method. In other words, each paper is counted once for each country listed in the address field. For example if a paper is authored by two researchers from Germany and one from Spain, this paper is counted once for each country.

Finally, with the aim of exploring the existence of a possible relationship between the interest of different countries in that topic and the existence of a broad spectrum of gender inequalities in these countries, the most recent GII was considered. GII is a new index for measuring gender disparity that was introduced in the 2010 Human Development Report (20th anniversary edition) of the United Nations Development Program (UNDP). According to the UNDP (2013), this index is a composite measure which yields insights, within the same country, about gender gaps in major areas of human development. It uses three dimensions to do so: reproductive health, measured by maternal mortality ratio and adolescent birth rates; empowerment, measured by proportion of parliamentary seats occupied by females and proportion of adult females and males aged 25 years and older with at least some secondary education; and labour market participation measured by employment rates of female and male populations aged 15 years and older. The GII values range between 0 to 1 , where a value close to 0 means equality between genders and a value close to 1 means inequality.

\section{Results}

\section{Number of papers}

Data showed an upward trend in the percentage of publications, $52.29 \%$ of which appeared in the last 7 years (2006-2012). The linear, exponential, and logistic regression 
models were fitted in order to test whether the data followed Price's law. Although all three regression models were statistically significant and captured a high proportion of the explained variance, the exponential model $\left(R^{2}=.834\right)$ explained a higher proportion of the variance than did either the linear $\left(R^{2}=.707\right)$ or logistic $\left(R^{2}=.578\right)$ approaches, showing a good fit to Price's law (Fig. 2).

An upward trend was also observed in the three main topics of the field. Table 1 shows the frequency, percentage, and regression fit for the three topics. As can be seen from the table, the research line with the highest frequency of papers was issues related to gender in academia and science. Furthermore, all the topics showed a good fit to the exponential model.

\section{Research areas}

According to the classification of journal areas used in Thomson Reuters WOS, the top ten research areas in terms of frequency of papers were Education and Educational Research $(n=71,18.3 \%)$, Psychology $(n=237,11.7 \%)$, Information Science and Library Science $(n=212,10.5 \%)$, Business and Economics $(n=167,8.2 \%)$, Women's Studies $(n=165,8.1 \%)$, Computer Science $(n=95,4.7 \%)$, Sociology $(n=93,4.6 \%)$, General and Internal Medicine $(n=63,3.1 \%)$, Health Care Sciences and Services $(n=58$, $2.9 \%)$, and, finally, Science and Technology-Other Topics $(n=53,2.6 \%)$.

Figure 3 shows the contribution of these top ten research areas in the three topics. Information Science and Library Science was the research area with the highest number of publications $(n=90,30.41 \%)$ in topic 1 followed by Computer Science $(n=48$, $20.61 \%)$. Education and Educational Research and Psychology were the research areas with the highest number of publications in topics 2 and 3. Education and Educational Research corresponds respectively to $27.03 \%(n=276)$ of publications in topic 2 and $28.45 \%(n=132)$ in topic 3, while Psychology corresponds respectively to $14.99 \%$ $(n=153)$ of publications in topic 2 and $20.26 \%(n=94)$ in topic 3.

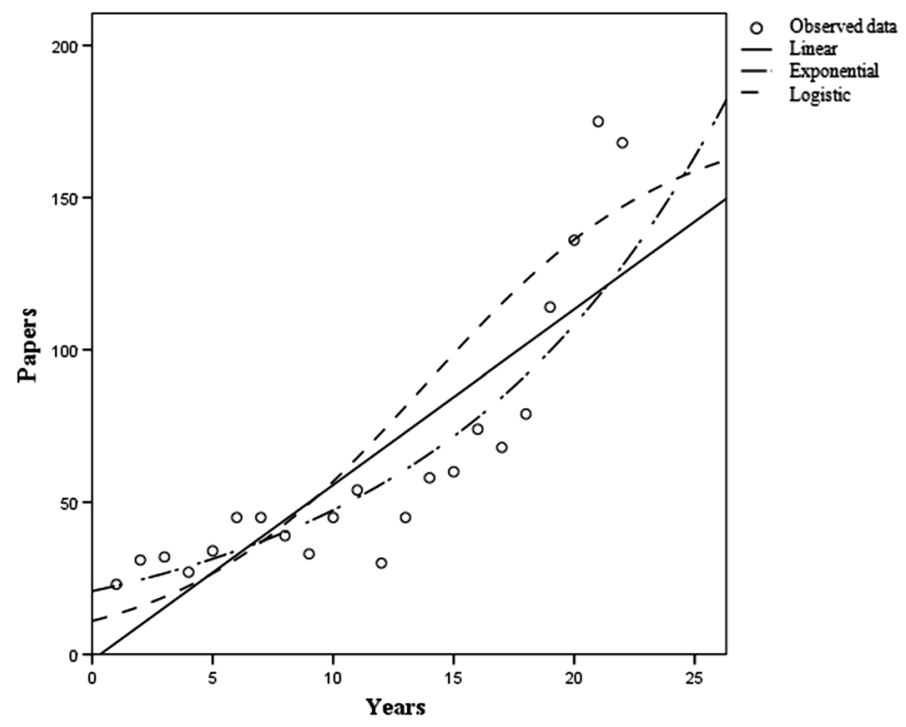

Fig. 2 Growth of literature over time (1991-2012): linear, exponential and logistic regression model fit to Price's law 
Table 1 Growth of literature over time (1991-2012) by topic: publication frequency and regression fit

\begin{tabular}{lllll}
\hline Topic & $f_{i}(\%)^{\mathrm{a}}$ & $R^{2}$ linear & $R^{2}$ exponential & $R^{2}$ logistic \\
\hline 1. Publication productivity & $275(19.43)$ & .597 & .677 & .578 \\
2. Issues related to gender in academia and science & $943(66.64)$ & .708 & .779 & .596 \\
3. Factors related to gender bias & $438(30.95)$ & .657 & .726 & .581 \\
\hline
\end{tabular}

fi frequency

a Note that a given paper may simultaneously address different topics. Consequently, the sum of papers is more than the total number of papers, and the sum of percentages exceeds $100 \%$

\section{Number of authors}

The total number of authors who contributed to the output set was 3064, with the mean number of authors per article being $2.41(\mathrm{SD}=1.60, \mathrm{M}=2)$. The data showed that 477 $(33.71 \%)$ of the papers had a single author, $398(28.12 \%)$ had two, $266(18.79 \%)$ had three, and $274(19.36 \%)$ had more than three authors. It can be seen in Fig. 4 that the number of papers with a single author showed a decreasing trend, whereas the number of papers with three authors and with more than three authors increased slightly over time. Over the same period there was a fluctuation in the number of papers with two authors.

With regard to the productivity of authors the data showed that $2750(89.75 \%)$ of them contributed with just one item to the field. Lotka's law was applied using the method proposed by Pao (1985), and all the authors of publications (first authors and collaborators) were considered for the analysis. To determine whether the data fitted Lotka's law, the $n$ value was calculated using the least squares method $(n=3.40)$, yielding a $C$ value of 0.88 . The critical value obtained by the non-parametric Kolmogorov-Smirnov goodnessof-fit test was 0.029 . As the maximum difference between the observed and the estimated accumulated frequencies was 0.014 , which is below the critical value, we can conclude that the data fitted Lotka's law.

\section{Countries}

Sixty-seven countries participated in publishing the set of studies, although it should be noted that the provenance of authors was not available for 204 papers $(14.4 \%)$. Only $8 \%$ $(n=113)$ of papers involved international collaboration and of these, $22.12 \%(n=25)$ were published recently (in 2012). The top ten countries in terms of absolute contributions, RII, and IC-RII are shown in descending order in Table 2. While the United States and United Kingdom are the most productive countries in terms of absolute contributions, Nicaragua and Botswana, based on the RII, are the countries that showed the highest proportion of publications in WSHE relative to the proportion of the world in the same area. Taking into account just those papers published in international collaboration, based on the IC-RII, Sudan, Nepal and Ghana are the countries with the highest international collaboration productivity.

Interestingly, a significant positive correlation coefficient was obtained between the most recent GII and the RII $(r=.277, p=.029)$ and the IC-RII $(r=.497, p=.001)$, showing that countries that present higher gender inequalities present higher relative productivity related to the topic as well as higher levels of international collaboration productivity. As the GII was not available for five countries, only 62 countries were considered in the analysis of the above-mentioned correlations. 
Topic 1- "Publication productivity"

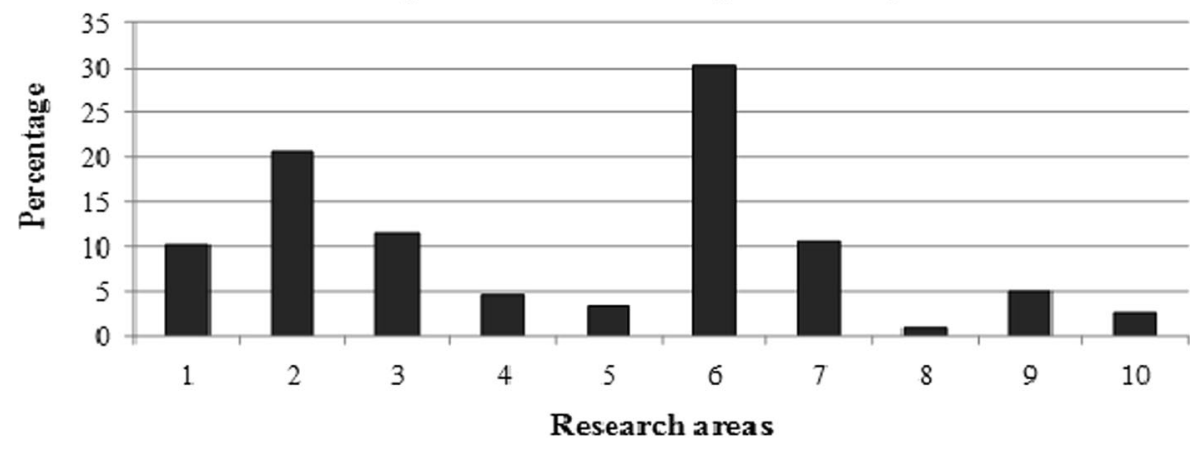

Top ic 2- "Issues related to gender in academia and science"

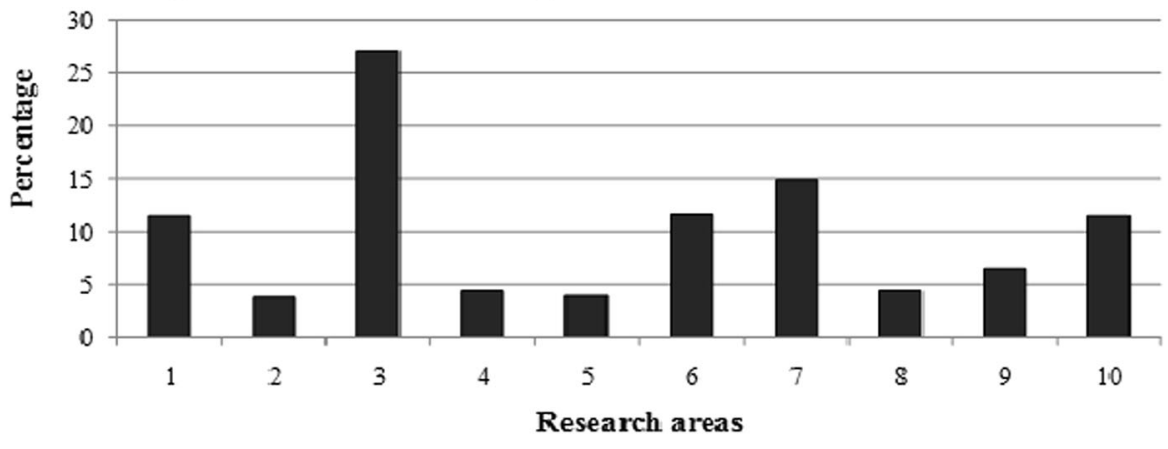

Topic 3- "Factors related to gender bias"

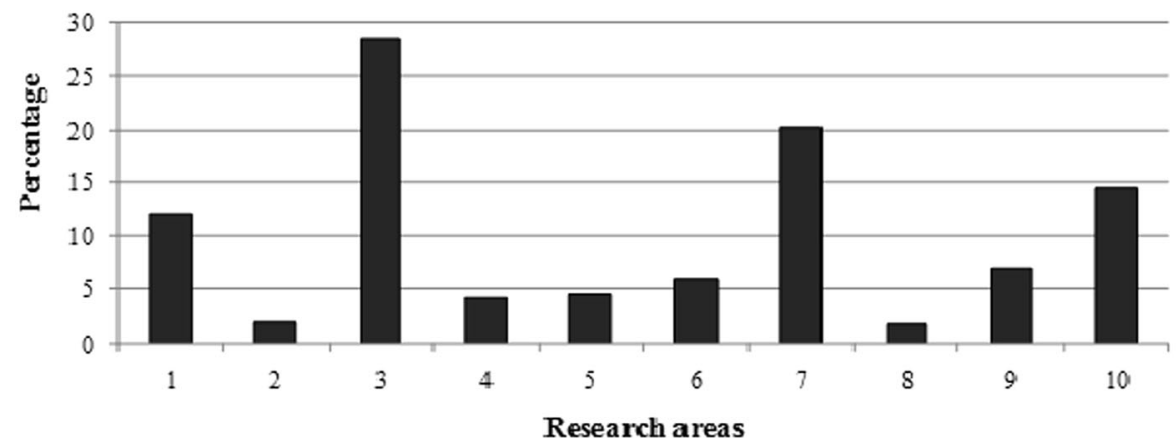

Fig. 3 Percentage of papers for the top ten research areas in the three topics. 1 Business and Economics, 2 Computer Science, 3 Education and Educational Research, 4 General and Internal Medicine, 5 Health Care and Services, 6 Information Science and Library Science, 7 Psychology, 8 Science and Technology-Other Topics, 9 Sociology, 10 Women's Studies

Regarding the topics, Issues related to gender in academia and science (topic 2) was the most frequent among the top ten countries in terms of absolute frequency. Among the papers involving international collaboration, $56.64 \%(n=64)$ of them dealt with the topic of issues related to gender in academia and science, $30.08 \%(n=34)$ addressed factors related to gender bias, and $28.31 \%(n=32)$ examined publication productivity. As any 


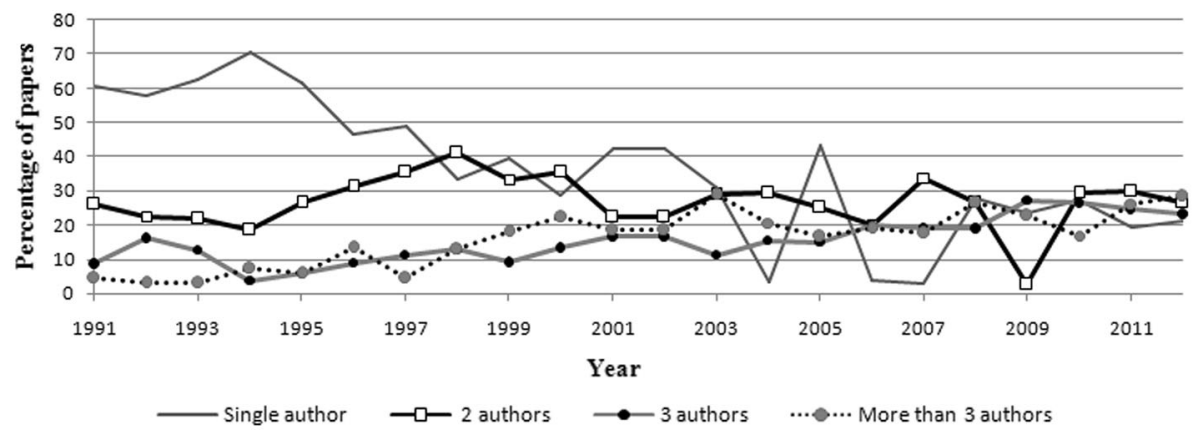

Fig. 4 Changes over time (1991-2012) in the number of authors per paper

Table 2 Top ten countries based on absolute contributions, relative intensity index (RII), and international collaboration relative intensity index (IC-RII)

\begin{tabular}{lclllr}
\hline Country & $f_{i}(\%)$ & Country & RII & Country & IC-RII \\
\hline USA & $638(45.08)$ & Nicaragua & 20.94 & Sudan & 35.33 \\
UK & $126(8.90)$ & Botswana & 6.24 & Nepal & 24.69 \\
Canada & $70(4.94)$ & Sudan & 5.47 & Ghana & 21.39 \\
Australia & $63(4.45)$ & Cyprus & 4.86 & Philippines & 18.02 \\
Spain & $57(4.02)$ & Nepal & 4.50 & Luxembourg & 17.65 \\
Germany & $41(2.89)$ & Lebanon & 3.83 & Cyprus & 15.18 \\
Netherlands & $29(2.04)$ & Luxembourg & 3.54 & Lebanon & 14.41 \\
Sweden & $29(2.04)$ & Ghana & 3.21 & Malaysia & 14.39 \\
China & $20(1.41)$ & Philippines & 3.03 & Bangladesh & 9.09 \\
Brazil/Italy/Turkey & $17(1.20)$ & SriLanka & 2.93 & Turkey & 6.78 \\
\hline
\end{tabular}

$f_{i}$ frequency

given paper may simultaneously address more than one topic, the sum of papers is more than the total number of papers, and the sum of percentages exceeds $100 \%$.

\section{Journals}

The papers included in the present study were published in a total of 595 journals, of which $366(61.5 \%)$ published only one paper. The distribution of papers published in the set of journals was described using Bradford's law, which revealed that the papers were distributed in four zones. The core was composed of 13 journals. Table 3 shows the expected number of journals given the Bradford multiplier (3.17), the actual number of journals in each zone, the number of articles included in each zone, the cumulative number of articles, the estimated values of $k$, and, finally, the predicted cumulative number of articles $R(r)$.

Table 4 shows core journals, publication frequency and the corresponding research areas of each journal based on the Thomson Reuters WOS. As can be seen from the table, six of the core journals belong to the area of Education and Educational Research, and Scientometrics is the journal with the highest number of papers related to topic 1, while the rest of the journals published more papers related to topic 2 . 
Table 3 Data fit to Bradford's law

\begin{tabular}{llllllr}
\hline Zone & $\begin{array}{l}\text { Expected number } \\
\text { of journals }\end{array}$ & $\begin{array}{l}\text { Number of } \\
\text { journals }\end{array}$ & $\begin{array}{l}\text { Number of } \\
\text { articles }\end{array}$ & $\begin{array}{l}\text { Cumulative } \\
\text { articles }\end{array}$ & Estimated $k$ & $R(r)$ \\
\hline 1 & 13 & 13 & 366 & 366 & - & 355.86 \\
2 & 41.10 & 41 & 250 & 616 & 3.15 & 634.02 \\
3 & 129.98 & 130 & 343 & 959 & 3.17 & 959.77 \\
4 & 411 & 411 & 456 & 1415 & 3.16 & 1303.04 \\
\hline
\end{tabular}

Constants according to Leimkuhler's formulation were $A=306.26$ and $B=0.168$

\section{Discussion}

This study has analyzed the main bibliometric indicators in relation to the literature on women's participation in science and higher education. With regard to the number of publications, results showed a significant increase and interest in the field over the last 21 years, particularly since 2002, when a steady increase begins. This increment was supported by the fit of the data to Price's law, which indicates that productivity in the studied field shows an exponential growth. Of the three topics considered, namely publication productivity, issues related to gender in academia and science, and factors related to gender bias, the highest number of papers corresponded to the second topic (i.e., issues related to gender in academia and science), accounting for $66.64 \%$ of the total publications. This topic was also the most frequently addressed in papers involving international collaboration $(56.64 \%)$. This result may be due to the fact that this topic addresses a wide variety of issues such as a scientific career, having access to funding, mentoring and networking, and being a member of an editorial board or a peer reviewer, among others. Furthermore, these studies often consider the other two topics as well in an attempt to examine existing differences in academia and science by searching for explanatory factors, and they often using bibliometric indicators such as publication productivity.

Regarding the research areas showing the most interest in the studied field, it can be inferred that scholars from different disciplines, such as Education and Educational Research, Psychology, Information Science and Library Science, Computer Science, Business and Economics, and Women's Studies, among others, have all contributed to the field, thereby indicating a high degree of multidisciplinarity. However, the interest of these areas in the three different topics is quite unbalanced. Not surprisingly, Information Science and Library Science and Computer Science were the areas with the highest contributions in the third topic, publication productivity, while Education and Educational Research and Psychology were the areas with the highest weight in the topics "issues related to gender in academia and science", and "factors related to gender bias".

In addition, the result of Bradford's law identified a small set of core journals focused on the studied field, which were also from eleven different research areas. Ordered according to frequency these core journals correspond to the following areas: Computer Science; Information Science and Library Science; Psychology; Women's Studies; Education and Educational Research; Health Care Sciences and Services; Business and Economics; Public, Environmental, and Occupational Health; General and Internal Medicine; Obstetrics and Gynecology; and Psychiatry. This means that this field is widely scattered across journals of different disciplines and is regarded as relevant in many research areas. However, it should be noted that the most productive research area is 
Table 4 Core journals, the corresponding research area, total publication frequency and publication frequency in each topic (1991-2012)

\begin{tabular}{|c|c|c|c|c|c|}
\hline Core journal & Research area & $\begin{array}{l}\text { Total } f_{i} \\
(\%)\end{array}$ & $\begin{array}{l}\text { Topic } 1^{\mathrm{a}} \\
f_{i}(\%)\end{array}$ & $\begin{array}{l}\text { Topic } 2^{\mathrm{a}} \\
f_{i}(\%)\end{array}$ & $\begin{array}{l}\text { Topic } 3^{\mathrm{a}} \\
f_{i}(\%)\end{array}$ \\
\hline Scientometrics & $\begin{array}{l}\text { Computer Science; Information } \\
\text { Science and Library Science }\end{array}$ & $57(15.57)$ & $45(78.95)$ & $20(35.09)$ & $2(3.51)$ \\
\hline Sex roles & Psychology; Women's Studies & $42(11.48)$ & $2(4.76)$ & $27(64.29)$ & $22(52.38)$ \\
\hline $\begin{array}{l}\text { Academic } \\
\text { medicine }\end{array}$ & $\begin{array}{l}\text { Education and Educational Research; } \\
\text { Health Care Sciences and Services }\end{array}$ & $39(10.66)$ & $7(17.95)$ & $27(69.23)$ & $16(41.03)$ \\
\hline $\begin{array}{l}\text { Higher } \\
\text { education }\end{array}$ & Education and Educational Research & $36(9.84)$ & $3(8.33)$ & $26(72.22)$ & $15(41.67)$ \\
\hline $\begin{array}{l}\text { Research in } \\
\text { higher } \\
\text { education }\end{array}$ & Education and Educational Research & $31(8.47)$ & $5(16.13)$ & $22(70.97)$ & $15(48.39)$ \\
\hline $\begin{array}{r}\text { Gender and } \\
\text { education }\end{array}$ & Education and Educational Research & $30(8.20)$ & $0(0.00)$ & $25(83.33)$ & $10(33.33)$ \\
\hline Scientist & $\begin{array}{l}\text { Information Science and Library } \\
\text { Science; Science And } \\
\text { Technology-Other Topics }\end{array}$ & $29(7.92)$ & $1(3.45)$ & $27(93.10)$ & $4(13.79)$ \\
\hline $\begin{array}{l}\text { Women's } \\
\text { studies } \\
\text { international } \\
\text { forum }\end{array}$ & Women's Studies & $19(5.19)$ & $1(5.26)$ & $15(78.95)$ & $6(31.58)$ \\
\hline $\begin{array}{l}\text { Gender work } \\
\text { and } \\
\text { organization }\end{array}$ & $\begin{array}{l}\text { Business and Economics; Women's } \\
\text { Studies }\end{array}$ & $18(4.92)$ & $0(0.00)$ & $12(66.67)$ & $9(50.00)$ \\
\hline $\begin{array}{l}\text { Journal of } \\
\text { higher } \\
\text { education }\end{array}$ & Education and Educational Research & $17(4.64)$ & $1(5.88)$ & $13(76.47)$ & $7(41.18)$ \\
\hline $\begin{array}{l}\text { Journal of } \\
\text { vocational } \\
\text { behavior }\end{array}$ & Psychology & 17 (4.64) & $0(0.00)$ & $13(76.47)$ & $5(29.41)$ \\
\hline $\begin{array}{l}\text { Journal of } \\
\text { womens' } \\
\text { health }\end{array}$ & $\begin{array}{l}\text { Public, Environmental and } \\
\text { Occupational Health; General and } \\
\text { Internal Medicine; Obstetrics and } \\
\text { Gynaecology; Women's Studies }\end{array}$ & $16(4.37)$ & $0(0.00)$ & $12(75.00)$ & $6(37.50)$ \\
\hline $\begin{array}{l}\text { Academic } \\
\text { psychiatry }\end{array}$ & $\begin{array}{l}\text { Education and Educational Research; } \\
\text { Psychiatry }\end{array}$ & $15(4.10)$ & $1(6.67)$ & $14(93.33)$ & $2(13.33)$ \\
\hline
\end{tabular}

$f_{i}$ frequency

a Some papers may simultaneously address more than one topic

Education and Educational Research, accounting for 6 of the 13 (46.15\%) core journals identified by Bradford's law.

With respect to the number of authors, a large number of papers $(477 ; 33.71 \%)$ are single author papers, suggesting that the scientific community in the field is composed of small groups and individual authors. Furthermore, author productivity was found to fit Lotka's law, indicating that there are a few, highly productive authors and a great majority who only contribute occasionally to research on WSHE. However, analysis of how the number of authors has evolved over time showed an increasing trend in terms of the number of papers being signed by three authors and by more than three authors, a trend that was paralleled by a clear reduction in the percentage of single-author papers. On the one 
hand, this may reflect the constitution of research groups, which is a feature associated with the consolidation of a field. On the other hand, and as has already been mentioned in other studies, this trend may be due to academic factors such as the increasing pressure to publish, the specialization of research expertise, collaborative efforts, or the interdisciplinarity of this field (Wren et al. 2007; Lozano 2013).

Authors contributing to the articles came from 67 different countries. It should be noted, however, that the increase in the number of authors and the high number of countries that contributed to the field have not been accompanied by greater international collaboration; only $8 \%$ of papers involved this kind of joint work, and the largest proportion of these were published recently. This indicates a field of study that has yet to become truly international and in which collaboration between countries and institutions needs to be reinforced.

The most productive countries, in absolute terms, are the United States and the United Kingdom, generating around half the total scientific production in this field (54\%). However, when RII, a relative measure to calculate country productivity, were used, Nicaragua and Botswana were the counties that showed the highest productivity in WSHE, relative to the proportion of the world in the same area. Similarly, when IC-RII were used to measure the relative proportion of publications of a country in international collaboration, Sudan, Nepal and Ghana were the countries that showed the highest international collaboration productivity.

With regard to the GII, the results showed a direct relationship between the most recent GII and the RII and IC-RII. This means that countries with higher GII values (higher inequality) are, in relative terms, the most productive in the field and are the most likely to collaborate internationally. Thus, although countries such as the United States and the United Kingdom are the most productive countries in terms of absolute contributions, countries with higher levels of inequality showed higher relative values of productivity in the field. This last finding is consistent with Glänzel's (2001) study, which analyzed country profiles and compared domestic and internationally co-authored papers. According to his findings, some countries compensate relatively weak domestic activities through international collaboration or even intensify their own strong activities in the preferred science fields by international collaboration. However, as Glänzel (2001) points out, international scientific collaboration has proved to be a complex and heterogeneous phenomenon which cannot be sufficiently characterized by bibliometric indicators alone.

In summary, the present study provides an overview of how scientific output in the field of WSHE has evolved over time. The results show that since 1991 until the present day there has been a clear upward trend in the number of publications, with increasing interest extending to many authors, countries, and scientific journals, as well as to several research areas. These results are consistent with Zosuls et al.'s (2011) conclusion that the growth in the diversity of topics covered by researchers over the past few decades has mainly been due to the multidimensionality of gender, and that the idea that the assumptions made about one domain of gender development can predict all others has come under serious scrutiny. Moreover, leaders in the field have encouraged increasingly precise and clear terminology, more sophisticated methods and analytic techniques, and a greater diversity of topics of study.

Overall, this increasing body of evidence shows that gender inequality remains a global problem, despite substantial initiatives and policies undertaken at national and international level (Larivière et al. 2013a, b). Although progress continues to be made, change is on average slow, patchy, and subject to significant variation according to country, research 
field, and other factors (LERU 2012). Numerous scholars from different parts of the world continue to address this problem and provide valuable material for evidence-based policies.

\section{References}

Aarssen, L., Tregenza, T., Budden, A. E., Lortie, C. J., Koricheva, J., \& Leimu, R. (2008). Bang for your buck: Rejection rates and impact factors in ecological journals. The Open Ecology Journal, 1, 114-119. doi:10.2174/1874213000801010014.

Allison, P. D., \& Long, J. S. (1990). Departmental effects on scientific productivity. American Sociological Review, 55(4), 469-478. doi:10.2307/2095801.

Andersen, H. (2001). The norm of universalism in sciences. Social origin and gender of researchers in Denmark. Scientometrics, 50(2), 255-272. doi:10.1023/A:1010521606702.

Arensbergen, P., van der Weijden, I., \& Besselaar, P. (2012). Gender differences in scientific productivity: A persisting phenomenon? Scientometrics, 93(3), 857-868. doi:10.1007/s11192-012-0712-y.

Blake, M., \& La Valle, I. (2000). Key factors shaping funding application behaviour among women and men in British higher education institutions. London: Wellcome Trust.

Bordons, M., Morillo, F., Fernández, M. T., \& Gómez, I. (2003). One step further in the production of bibliometric indicators at the micro level: Differences by gender and professional category of scientists. Scientometrics, 57(2), 159-173. doi:10.1023/A:1024181400646.

Bornmann, L., Mutz, R., \& Daniel, H. D. (2007). Gender differences in grant peer review: A meta-analysis. Journal of Informetrics, 1(3), 226-238. doi:10.1016/j.joi.2007.03.001.

Borrego, Á., Barrios, M., Villarroya, A., \& Ollé, C. (2010). Scientific output and impact of postdoctoral scientists: A gender perspective. Scientometrics, 83(1), 93-101. doi:10.1007/s11192-009-0025-y.

Boschini, A., \& Sjögren, A. (2007). Is team formation gender neutral? Evidence from co-authorship patterns. Journal of Labor Economics, 25(2), 325-365. doi:10.1086/510764.

Bradford, S. C. (1934). Sources of information on specific subjects. Engineering, 23(3), 85-88.

Bradford, S. C. (1948). Documentation. London: Crosby Lockwood.

Braisher, T. L., Symonds, M. R. E., \& Gemmell, N. J. (2005). Publication success in nature and science is not gender dependent. BioEssays, 27(8), 858-859. doi:10.1002/bies.20272.

Budden, A. E., Tregenza, T., Aarssen, L. W., Koricheva, J., Leimu, R., \& Lortie, C. J. (2008). Double-blind review favors increased representation of female authors. Trends in Ecology \& Evolution, 23(1), 4-6. doi:10.1016/j.tree.2007.07.008.

Cole, J. R., \& Zuckerman, H. T. (1984). Advances in motivation and achievement. In M. W. Steinkamp \& M. L. Maehr (Eds.), The productivity puzzle: Persistence and change in patterns of publication of men and women scientists (pp. 217-256). Greenwich, CT: JAI.

Commission, European. (2009). The gender challenge in research funding. Assessing the European national scenes. Brussels: Directorate General for Research and Innovation.

Commission, European. (2013). She figures 2012. Gender in research and innovation. Brussels: Directorate General for Research and Innovation.

Copenheaver, C. A., Goldbeck, K., \& Cherubini, P. (2010). Lack of gender bias in citation rates of publications by dendrochronologists: What is unique about this discipline? Tree-Ring Research, 66(2), 127-133. doi:10.3959/2009-10.1.

D’Amico, R., Vermigli, P., \& Canetto, S. S. (2011). Publication productivity and career advancement by female and male psychology faculty: The case of Italy. Journal of Diversity in Higher Education, 4(3), 175-184. doi:10.1037/a0022570.

Davo, M. D. C., Vives, C., \& Álvarez-Dardet, C. (2003). Why are women underused in the JECH peer review process? Journal of Epidemiology and Community Health, 57(12), 936-937. doi:10.1136/jech. 57.12.93.

Deloitte Consulting. (2013). Researchers' report 2013. Brussels: European Commission's DirectorateGeneral for Research and Innovation.

DesRoches, C. M., Zinner, D. E., Rao, S. R., Iezzoni, L. I., \& Campbell, E. G. (2010). Activities, productivity, and compensation of men and women in the life sciences. Academic Medicine, 85(4), 631-639. doi:10.1097/ACM.0b013e3181d2b095.

Dewandre, N. (2002). European strategies for promoting women in science. Science, 295(5553), 278-279. doi:10.1126/science. 1063487. 
Dickersin, K., Fredman, L., Flegal, K. M., Scott, J. D., \& Crawley, B. (1998). Is there a sex bias in choosing editors? Epidemiology journals as an example. Journal of the American Medical Association, 280(3), 260-264.

Egghe, L. (1986). The dual of Bradford's law. Journal of the American Society for Information Science, 37(4), 246-255.

Egghe, L. (1990). Applications of the theory of Bradford's law to the calculation of Leimkuhler's law and to the completion of bibliographies. Journal of the American Society for Information Science, 41(7), 469-492.

Fox, M. F. (2005). Gender, family characteristics, and publication productivity among scientists. Social Studies of Science, 35(1), 131-150. doi:10.1177/0306312705046630.

Gilbert, J. R., Williams, E. S., \& Lundberg, G. D. (1994). Is there gender bias in JAMA's peer review process? Journal of the American Medical Association, 272(2), 139-142. doi:10.1001/jama.1994. 03520020065018 .

Ginther, D. K. (2003). Is MIT an exception? Gender pay differences in academic science. Bulletin of Science, Technology \& Society, 23(1), 21-26. doi:10.1177/0270467602239767.

Ginther, D., \& Kahn, S. (2006). Does science promote women? Evidence from academia 1973-2001. In R. B. Freeman \& D. Goroff (Eds.), The science and engineering careers in the United States (pp. 163-194). Chicago: University of Chicago Press for the National Bureau of Economic Research.

Glänzel, W. (2001). National characteristics in international scientific co-authorship relations. Scientometrics, 51(1), 69-115. doi:10.1023/A:1010512628145.

Gonzalez-Brambila, C., \& Veloso, F. M. (2007). The determinants of research output and impact: A study of Mexican researchers. Research Policy, 36(7), 1035-1051. doi:10.1016/j.respol.2007.03.005.

Henderson, M. T., Fijalkowski, N., Wang, S. K., Maltenfort, M., Zheng, L. L., Ratliff, J., et al. (2014). Gender differences in compensation in academic medicine: The results from four neurological specialties within the University of California Healthcare System. Scientometrics, 100(1), 297-306. doi:10.1007/s11192-014-1266-y.

Hunter, L. A., \& Leahey, E. (2010). Parenting and research productivity: New evidence and methods. Social Studies of Science, 40(3), 433-451. doi:10.1177/0306312709358472.

Isaac, C., Lee, B., \& Carnes, M. (2009). Interventions that affect gender bias in hiring: A systematic review. Academic Medicine, 84(10), 1440-1446. doi:10.1097/ACM.0b013e3181b6ba00.

Jagsi, R., DeCastro, R., Griffith, K. A., Rangarajan, S., Churchill, C., Stewart, A., \& Ubel, P. A. (2011). Similarities and differences in the career trajectories of male and female career development award recipients. Academic Medicine, 86(11), 1415-1421. doi:10.1097/ACM.0b013e3182305aa6.

Kelly, C. D., \& Jennions, M. D. (2006). The h index and career assessment by numbers. Trends in Ecology \& Evolution, 21(4), 167-170. doi:10.1016/j.tree.2006.01.005.

Larivière, V., Diepeveen, S., Ni, C., Macaluso, B., Pollitt, A., \& Grant, J. (2013a). International comparative performance of mental health research, 1980-2011. European Neuropsychopharmacology, 23(11), 1340-1347. doi:10.1016/j.euroneuro.2013.01.006.

Larivière, V., Ni, C., Gingras, Y., Cronin, B., \& Sugimoto, C. R. (2013b). Bibliometrics: Global gender disparities in science. Nature, 504(7479), 211-213. doi:10.1038/504211a.

Larivière, V., Vignola-Gagné, E., Villeneuve, C., Gélinas, P., \& Gingras, Y. (2011). Sex differences in research funding, productivity and impact: An analysis of Québec university professors. Scientometrics, 87(3), 483-498. doi:10.1007/s11192-011-0369-y.

Leahey, E. (2006). Gender differences in productivity: Research specialization as a missing link. Gender \& Society, 20(6), 754-780. doi:10.1177/0891243206293030.

Ledin, A., Bornmann, L., Gannon, F., \& Wallon, G. (2007). A persistent problem. EMBO Report, 8(11), 982-987. http://www.nature.com/embor/journal/v8/n11/suppinfo/7401109_S1.html.

Leimkuhler, F. F. (1967). The Bradford distribution. Journal of Documentation, 23(3), 197-207.

Lemoine, W. (1992). Productivity patterns of men and women scientists in Venezuela. Scientometrics, 24(2), 281-295. doi:10.1007/BF02017912.

LERU (League of European Research Universities). (2012). Women, research and universities: Excellence without gender bias. Leuven: League of European Research Universities.

Leta, J., \& Lewison, G. (2003). The contribution of women in Brazilian science: A case study in astronomy, immunology and oceanography. Scientometrics, 57(3), 339-353. doi:10.1023/A:1025000600840.

Lewison, G. (2001). The quantity and quality of female researchers: A bibliometric study of Iceland. Scientometrics, 52(1), 29-43. doi:10.1023/A:1012794810883.

Long, J. S. (1992). Measures of sex differences in scientific productivity. Social Forces, 71(1), 159-178. doi:10.1093/sf/71.1.159.

Lozano, G. A. (2013). The elephant in the room: Multi-authorship and the assessment of individual researchers. Current Science, 105(4), 443-445. 
Marsh, H. W., Bornmann, L., Mutz, R., Daniel, H. D., \& O’Mara, A. (2009). Gender effects in the peer reviews of grant proposals: A comprehensive meta-analysis comparing traditional and multilevel approaches. Review of Educational Research, 79(3), 1290-1326. doi:10.3102/0034654309334143.

Marsh, H. W., Jayasinghe, U. W., \& Bond, N. W. (2008). Improving the peer-review process for grant applications: Reliability, validity, bias, and generalizability. American Psychologist, 63(3), 160-168. doi:10.1037/0003-066X.63.3.160.

Maske, K. L., Durden, G. C., \& Gaynor, P. E. (2003). Determinants of scholarly productivity among male and female economists. Economic Inquiry, 41(4), 555-564. doi:10.1093/ei/cbg027.

Mauleón, E., \& Bordons, M. (2006). Productivity, impact and publication habits by gender in the area of materials science. Scientometrics, 66(1), 199-218. doi:10.1007/s11192-006-0014-3.

Mauleón, E., Bordons, M., \& Oppenheim, C. (2008). The effect of gender on research staff success in life sciences in the Spanish National Research Council. Research Evaluation, 17(3), 213-225. doi:10.3152/ $095820208 \times 331676$.

McDowell, J. M., Singell, L. D., \& Stater, M. (2006). Two to tango? Gender differences in the decisions to publish and coauthor. Economic Inquiry, 44(1), 153-168. doi:10.1093/ei/cbi065.

Moss-Racusin, C. A., Dovidio, J. F., Brescoll, V. L., Graham, M. J., \& Handelsman, J. (2012). Science faculty's subtle gender biases favor male students. Proceedings of the National Academy of Sciences, 109(41), 16474-16479. doi:10.1073/pnas.1211286109.

Mutz, R., Bornmann, L., \& Daniel, H. D. (2012). Does gender matter in grant peer review? An empirical investigation using the example of the Austrian science fund. Z Psychol, 220(2), 121-129. doi:10.1027/ 2151-2604/a000103.

OECD. (2013). Education at a glance 2013: OECD indicators. Paris: OECD.

Pao, M. L. (1985). Lotka law: A testing procedure. Information Processing and Management, 21(4), $305-320$.

Pashkova, A. A., Svider, P. F., Chang, C. Y., Diaz, L., Eloy, J. A., \& Eloy, J. D. (2013). Gender disparity among US anesthesiologists: Are women underrepresented in academic ranks and scholarly productivity? Acta Anaesthesiologica Scandinavica, 57(8), 1058-1064. doi:10.1111/aas.12141.

Price, D. J. D. S. (1963). Little science, big science. New York: Columbia University Press.

Prozesky, H. (2008). A career-history analysis of gender differences in publication productivity among South African academics. Science Studies, 21(2), 47-67.

Puuska, H. M. (2010). Effects of scholar's gender and professional position on publishing productivity in different publication types. Analysis of a Finnish university. Scientometrics, 82(2), 419-437. doi:10. 1007/s11192-009-0037-7.

Ranga, M., Gupta, N., \& Etzkowitz, H. (2012). Gender effects in research funding. Bonn: Deutsche Forschungsgemeinschaft.

Sax, L., Hagedorn, L., Arredondo, M., \& Dicrisi, F., I. I. I. (2002). Faculty research productivity: Exploring the role of gender and family-related factors. Research in Higher Education, 43(4), 423-446. doi:10. 1023/A:1015575616285.

Schrager, S., Bouwkamp, C., \& Mundt, M. (2011). Gender and first authorship of papers in family medicine journals 2006-2008. Family Medicine, 43(3), 155-159.

Shen, H. (2013). Inequality quantified: Mind the gender gap. Nature, 495(7439), 22-24. doi:10.1038/ $495022 \mathrm{a}$

Sidhu, R., Rajashekhar, P., Lavin, V. L., Parry, J., Attwood, J., Holdcroft, A., \& Sanders, D. S. (2009). The gender imbalance in academic medicine: A study of female authorship in the United Kingdom. Journal of the Royal Society of Medicine, 102(8), 337-342. doi:10.1258/jrsm.2009.080378.

Snell, C., Sorensen, J., Rodriguez, J. J., \& Kuanliang, A. (2009). Gender differences in research productivity among criminal justice and criminology scholars. Journal of Criminal Justice, 37(3), 288-295. doi:10. 1016/j.jcrimjus.2009.04.009.

Sonnert, G. (1996). Gender equity in science: Still an elusive goal. Issues in Science and Technology, 12(2), 53-58.

Stack, S. (2004). Gender, children and research productivity. Research in Higher Education, 45(8), 891-920. doi:10.1007/s11162-004-5953-z.

Symonds, M. R., Gemmell, N. J., Braisher, T. L., Gorringe, K. L., \& Elgar, M. A. (2006). Gender differences in publication output: Towards an unbiased metric of research performance. PLoS One, 1, e127. doi:10.1371/journal.pone.0000127.

Taylor, S. W., Fender, B. F., \& Burke, K. G. (2006). Unraveling the academic productivity of economists: The opportunity costs of teaching and service. Southern Economic Journal, 72(4), 846-859. doi:10. 2307/20111856.

Tower, G. D., Plummer, J. A., \& Ridgewell, B. (2007). Multi-disciplinary study of gender-based research output in the world's best journals. Journal of Diversity Management, 2(4), 23-32. 
United Nations Development Programme. (2013). Gender inequality index (GII). Retrieved February 20, 2014, from http://hdr.undp.org/en/statistics/gii.

Van den Brink, M. (2011). Scouting for talent: Appointment practices of women professors in academic medicine. Social Science and Medicine, 72(12), 2033-2040.

Van den Brink, M., \& Benschop, Y. (2012). Gender practices in the construction of academic excellence: Sheep with five legs. Organization, 19(4), 507-524.

Waisbren, S. E., Bowles, H., Hasan, T., Zou, K. H., Emans, S. J., Goldberg, C., \& Christou, H. (2008). Gender differences in research grant applications and funding outcomes for medical school faculty. Journal of Women's Health (Larchmt), 17(2), 207-214. doi:10.1089/jwh.2007.0412.

Ward, M. (2001). The gender salary gap in British academia. Applied Economics, 33(13), 1669-1681. doi:10.1080/00036840010014445.

Ward, J. E., \& Donnelly, N. (1998). Is there gender bias in research fellowships awarded by the NHMRC? Medical Journal of Australia, 169(11-12), 623-624.

Webster, B. M. (2001). Polish women in science: A bibliometric analysis of Polish science and its publications, 1980-1999. Research Evaluation, 10(3), 185-194. doi:10.3152/147154401781776999.

Wellcome Trust. (1997). Women and peer review an audit of the Wellcome Trust's decision-making on grants (PRISM report no. 8). London: Wellcome Trust.

Wennerås, C., \& Wold, A. (1997). Nepotism and sexism in peer-review. Nature, 387(6631), 341-343. doi: $10.1038 / 387341 \mathrm{a} 0$.

West, J. D., Jacquet, J., King, M. M., Correll, S. J., \& Bergstrom, C. T. (2013). The role of gender in scholarly authorship. PLoS One, 8(7), e66212. doi:10.1371/journal.pone.0066212.

Whittaker, R. J. (2008). Journal review and gender equality: A critical comment on Budden et al. Trends in Ecology \& Evolution, 23(9), 478-479; author reply 480. doi:10.1016/j.tree.2008.06.003.

Wren, J. D., Kozak, K. Z., Johnson, K. R., Deakyne, S. J., Schilling, L. M., \& Dellavalle, R. P. (2007). The write position. EMBO Reports, 8(11), 988-991. doi:10.1038/sj.embor.7401095.

Xie, Y., \& Shauman, K. A. (1998). Sex differences in research productivity: New evidence about an old puzzle. American Sociological Review, 63(6), 847-870. doi:10.2307/2657505.

Zinovyeva, N., \& Bagues, M. (2011). Does gender matter for academic promotion? Evidence from a randomized natural experiment. IZA discussion paper no. 5537, Bonn, Germany.

Zosuls, K. M., Miller, C. F., Ruble, D. N., Martin, C. L., \& Fabes, R. A. (2011). Gender development research in sex roles: Historical trends and future directions. Sex Roles, 64(11-12), 826-842. doi:10. 1007/s11199-010-9902-3. 